Plenary Presentation for Universities Psychotherapy and Counselling Association Conference Novembe 22 2014, at Whitelands College Roehampton University, later published in European Journal of Psychotherapy \& Counselling, 17:3, 225-239

\title{
Psychotherapy in a Neoliberal World
}

\section{Michael Rustin}

Psychotherapy - therapies or treatments for the mind, are of a course a function, an activity performed in virtually all forms of society. In all societies, ndividuals at some times find it difficult to live as they wish to do, and societies sometimes find it difficult to tolerate difficulties among individuals, or their differences from prevailing norms. .

As we know, this 'therapeutic' function is performed in different ways within different kinds of social system. Sometimes exclusion, segregation or incarceration is the chosen means of dealing with the deviant. Even extermination can be resorted to, as with the Nazis. The mentally ill were confined to asylums and treated as a spectacle - a human zoo - in early modern Europe. Asylums continued long into the twentieth century even as the idea of spectacle came to seem undignified and inappropriate. Asylums continue to exist today. (For this history see Porter 2003, Scull 2005).

The professions of medicine, through the branch of psychiatry or psychological medicine, naturally laid claim from their beginnings to the sphere of mental as well as bodily disease. There is a remarkable scene in Macbeth, where responsibity for such conditions is debated between Macbeth and the Doctor, who has just witnessed Lady Macbeth's sleepwalking, and observed her as we would now say unconsciously confessing her guilt for the murder of King Duncan when he was guest in the Macbeths' castle:

MACBETH How does your patient, Doctor?

DOCTOR Not so sick, my Lord,

As she is troubled with thick-coming fancies,

That keep her from her rest.

Cure her of that: 
Canst thou not minister to a mind diseas'd,

Pluck from the memory a rooted sorrow,

Raze out the written trouble of the brain,

And with some sweet oblivious antidote

Cleanse the stuff'd bosom of that perilous stuff

Which weighs upon the heart?

DOCTOR

Therein the patient

Must minister to himself.

MACBETH Throw physic to the dogs; I'll none of it.

Come, put mine armour on; give me my staff. -

Seyton, send out -, Doctor, the Thanes fly from me. -

Come sir, despatch. - If thou could, Doctor,

Cast the water of my land, find her disease,

And purge it to a sound and pristine health,

I would applaud thee to the very echo,

That should applaud again. - Pull't off, I say -

What rhubarb, cime or what purgative drug,

Would scare these English hence? Hear'st thou of them?

DOCTOR Ay my good Lord, Your royal preparation

Makes us hear something.

Macbeth, Act V, 3. 37-68

The Doctor in the previous scene has heard Lady Macbeth tell of her and her husband's deeply criminal deeds, and he knows that having this knowledge places him at grave risk. Perhaps this is why he tells Macbeth that such disease is the patient's business - Macbeth's business indeed - and not a Doctor's. But note in this remarkable speech, written four hundred years ago, ${ }^{1}$ how the pharmaceutical future of psychiatric medicine is anticipated ('some sweet oblivious antidote') and also the temptations which rulers will later take up to engage psychiatrists, and even psychoanalysts, to aid them in destroying their enemies.

\footnotetext{
${ }^{1}$ Shakespeare has a great deal else to say in his plays about what we noiw call mental illness and how societies respond to it.
} 
Religious agencies - tribal medicines, churches, temples and mosques of all kinds and their priests and functionaries have also been very important in the management of mental illness or deviance within societies. Exorcism and persecution have been one of their approaches. In the light of psychoanalysis we can now interpret what was going on in such persecution and atrocity, for example in the treatment of witches, as a response to the fear aroused by mental illness, and its forcible projection and evacuation into convenient or vulnerable victims.

John Stuart Mill assigned as a cause of his psychological difficulties the barrenness of the excessively rationalist utilitarian thinking in which he had been reared (his father James Mill was a close associate of Jeremy Bentham), He attributed his recovery to his discover of poetry, and the opportunity this gave him to estabish contact with a world of feeling and the imagination. Thus literature and the arts entered modern psychological debate as potential contributions to mental well-being, a position that they have never since lost, among some parts of the population The concept of education in English literature advocated by F.R. Leavis and his followers, which has had considerable influence in Britain, saw the education of feelings as part of the function and purpose of reading.

Michel Foucault writing from his knowledge of, and no great love for, modern psychoanalysis, pointed to the similarities between the religious practices of confession, meditation and prayer, and the secular practices of psychoanalysis and psychotherapy. Both were about the investigation, preferably including selfinvestigation, of the soul, or mind, through the mediation or with the support of a priest, minister or a therapist. This was in order to bring about some greater accommodation between the state of mind of the individual and that which was normatively expected of him or her, including by him or herself.

Foucault (2006) argued that although on the surface modern psychotherapeutic 'technologies' for the management of the psyche might appear to be less harsh than earlier methods of punitive incarceration, ridicule and restraint of the mad, they were in fact more deeply intrusive and controlling. Their methods of investigating and 
'naming' in scientific and clinical discourses the different aspects and functions of the mind had the effect, Foucault wrote, of bringing these within the domain of regulation and self-regulation, in the name of 'science'.

Psychoanalysis and the modern psychotherapies derived from or cognate with it developed in the context of the secularisation of the mental universe of European city populations in the early twentieth century. In societies allowing considerable economic, social and cultural freedoms to its middle class populations, the idea that individuals could seek remedy for psychological difficulties, for mental suffering, by finding a professional practitioner who could be paid to provide this, seems a natural extension of other individual freedoms. The fact that Freud's ideas and clinical methods filled this space more pervasively than any other may be a more contingent fact than that some such individualised psychological therapy would emerge to dominance. One can surely imagine that the relative influence for example of Freud and Jung on subsequent development could have been reversed, with the followers of Jung achieving the dominant position. (Why this did not happen is itself an interesting counterfactual question for cultural historians $)^{2}$.

I've suggested in an earlier paper (Rustin 1984) that the idea of 'mental well-being' came to be defined as a good for which societies and their governments should take some responsibility, during the twentieth century. The idea that there had been an evolution over several centuries of rights and entitlements was put forward by $\mathrm{TH}$ Marshall in his essay 'Citizenship and Social Class' (Marshall 1963) as an explanatory rationale for the development of the welfare state. These included, in their approximate historical sequence, civil rights (the rule of law, freedom of speech); political rights (enfranchisement and democracy); economic rights (for trade unions and a minimum income); and social rights (for example to education and health care.) I suggested that rights to support for emotional and psychological wellbeing, for example during the inevitable stresses which occur in the transitions of the normal life-cycle (childbirth and the early years, in childhood, during illness, and in

\footnotetext{
${ }^{2}$ It may be that the aspect of Freud's writing that caused most outrage - sexuality and infantile sexuality in particular - is what also gave them their particlar force.
} 
later llife and in bereavement and loss) could be seen and indeed welcomed as a further extension of this idea of social entitlements or rights.

The idea that there might be a moral entitlement, on the basis of common humanity and citizenship, to psychotherapeutic care, was taken seriously in the development of the psychoanalytic movement. Some of its practitioners did not think that the goods embodied in psychoanalytic practice should only be available to those individuals and families with the privileged economic resources to pay for them from their private wealth. Thus early on, and supported in principle by Freud, (Dantro 2005) were the ideas of publicly-funded clinics, such as were set up in Vienna and Berlin, and psychotherapeutically oriented day nurseries, such as Anna Freud's wartime nursery in London. The involvement of psychoanalysts in the treatment of the mentally ill, especially after the foundation of the NHS in 1947, and the development of 'child guidance clinics' (these began in the 1930s) and became CAMHS (child and adolescent mental health services) were broader implementations of these conceptions. John Bowlby was a strong supporter of the NHS (he was chair of the Child and Family Department at the Tavistock Clinic). His commitment to services to support child mental health, and that of Colin Murray Parkes, in regard to the care of the dying and support for the bereaved, are further important instances of the incorporation of the psychotherapeutic approaches into public welfare provision. The development of the hospice movement is an example of a convergence of religious and secular (indeed scientific) traditions in the support of mental health. (There are other convergences, since religious institutions still take responsibility for the care of those with long-term mental illnesses or disabilities which few purely secular institutions are able or willing to do. I remember the parents of a young patient of my wife's, who had very severe pschological disabilities amounting to intermittent psychotic states, found that a hostel owned and managed by a religious order were better able to share her care with her family than any other available agency).

What was achieved in this post-war 'welfare development' was a kind of 'mixed economy' of mental health care (paralleling many other 'mixed economies' in Britain) in which the priviate professions of psychoanalysis and psychotherapy, and their trainings, co-existed with the 'public economy' of NHS mental health provision. In 
psychoanalysis a kind oif 'dual leadership', by the British Psychoanalytical Society on the 'private' side, and the Tavistock Clinic on the 'public side' had leading roles, with many more and less visible exchanges of personnel, knowledge and training between them. But although considerable professional, intellectual, and service developments in psychoanalytic psychotherapies did take place during this period (from 1940 or so until perhaps the emergence of the present Coalition government) these therapies were always a minority sector in the broader provison of mental health services, in which medicalised and largely drug-based therapies have been the dominant element.

\section{Neoliberalism and its consequences}

This brings us to neoliberalism and the present day.

Neoliberalism is capitalism in the 'financialised' and 'globalised' form which has dominated the western world for more than thirty years, since the conservative resolution of the social crisis of the late 1960s and 1970s, which was really a counter-revolution. Its triumph signified the defeat or serious weakening of the social forces which had provided some balancing force to the power of capital and markets in the post-war period of the welfare settlement. The New Labour governments of the period from 1997-2010 attempted to achieve some new balance between 'public' and 'private' provision. They continued the marketisation of the public sector, through 'outsourcing' and the imposition of new forms of management modelled on those of private corporations. But at the same time they sought to improve standards in public services and increased the resources available to them. Important new initiatives, such as Surestart and the extension of nursery care, took place during this time. This uneasy and indeed contradictory balance of purposes and ideologies came to a disastrous end in the financial crash of 2007-8, which revealed an economy whose apparent prosperity had been too heavily based on over-inflated financial and property sectors.

Throughout this period the ideology of the neoliberal regime was having significant consequences for the psychotherapies, even while governments were still supporting 
some positive developments in this sphere. In particular, there has been a steady erosion of the idea that individuals are deserving of support from society and government when they need it, for example in managing the inevitably stressful conditions and transitions of the life cycle. (The early years, adolescence the transition from school or college to employment, sickness, old age and bereavement). This conception of social membership and mutual responsibility is being corrosively undermined and displaced by an ideology of total individual selfresponsibility. 'There is no such thing as society', as Mrs Thatcher memorably put it.

The transformation of higher education from what was essentially a gift from one generation to the next - to its collective children - to a calculated investment by the young in their own future careers - is an emblematic example of this change in world-view. With characteristic populist hypocrisy this change was introduced in part on the grounds that funding the development of the minority of the age-group who qualified for university was unjust to those who didn't qualify. This ignored, of course the alternative option, if it was fairness one was really concerned about, of supporting post-school education and training for all young people. An implicit purpose of this' individualisation' of education, and financial responsibility, must be to inculcate in students a primary preoccupation with their own future financial interests (they will have huge debts to pay off), at the expense of the more intrinsic or altruistic motivations they might otherwise have sustained. Thus the earlier promise of what might have been achieved, - a democratic society, open and committed to learning through universal access to post-school education is defeated. The 'privatisation' of academic knowledge, and the stratification of educational institutions at all levels, inherent in the Research Excellence Framework and in the grading procedures of the inspectorates further undercut the values of educational democracy. In the early days of the Coalition, the fact that the individualist and competitive weakening of social bonds and cohesion might be a problem was even acknowledged in David Cameron's 'Big Society' rhetoric, but very little came of this and it has disappeared from political view. Those psychotherapies framed around relational conceptions of the self and society find themselves particularly out of key with this dominant way of thinking. 
Although neoliberal ideology gives priority to the market as the primary organiser of social life, and as the primary engine of people's well-being, government neverthless occupies a forceful role in this system. This is as the enforcer of market principles, and as supporter of the corporate interests for whose immediate benefit the market is permitted to operate. Since the private economy is held to be the primary generator of wealth and thus (according to this model) well-being, and since the competitiveness of the British economy is essential to this, many institutions are bent to the purpose of a functioning market. Education becomes defined mainly as the production of employable human outputs. Social protection is rationed to enforce participation in the workforce. The advocacy of mental health treatment in the Increased Access to Psychological Therapies, (IAPT) initiated under the previous government to address the huge scale of untreated mental illness, has as one of its justifications the prospect of returning those who have received successful treatment to the labour market.

The programme of this Conference gives considerable emphasis to changes in what Marxist social scientists used to call the labour process which are taking place, indeed are being imposed, in this neoliberal era. Models for the efficient organisation of production and of distribution, whose origin lay in the corporate sector, and in manufacturing in particular, are being applied to the delivery of services in the public sector. This process by which less efficient forms of production are defeated in the competition of the market by more efficient (cost-effective) forms has obviously been transformative for as long as capitalism has existed. What is new is the expectation and requirement that public enterprises, authorised by law and intended to produce 'social' goods like health, welfare and education operate according to similar rules as those in the profit-making sphere.

Since such public goods are not in reality 'sold' to their users, but are nevertheless ostensibly provided in response to their 'consumer choice' targets and measures have to be created, and then assessments of achievement made, ranked and displayed, to faciltate choice, and also to ensure the most efficient use of resources. The insistence that medical care must be 'evidence-based' is an aspect of this system in operation. The arguments and struggles that have taken place since the 
beginnings of industrialisation, in which established 'craft' methods of production are rendered un-economic by the introduction of machinery or rationalised forms of work-organisation (the mass production assembly line, or the call centre) become progressively replicated in other fields, including those of health care and education.

In the mental health sphere, the development of IAPT, with its favouring of CBT over other therapies, and manualised 'mentalisation' programmes, are examples of such rationalised innovation. There is also an element of marketisation in the contemporary development of 'branding' and in effect selling of such therapeutic interventions as 'packages' or franchises.

The programme outline for this Conference calls upon the critiques of 'mechanisation', mass production and routinisation, advanced in the $19^{\text {th }}$ century by radical social critics such as Karl Marx, John Ruskin and William Morris, as being potentially relevant to the contemporary situation of psychotherapists.It is not difficult to see why psychotherapists and other professions too feel threatened and attacked by these developments, as indeed they are. Some professionals in public services have responded to this situation by withdrawing from it. One response is simply to join a system that it seems cannot be beaten, for example by working for corporate health providers. Another is to retreat to small-scale private practice, or to the charitable sector, where it is hoped that the intrinsic values and autonomy of the therapeutic professions can be to a degree protected.

If the sway of neoliberal ideology continues to grow, such migration will become more common. One can easily envisage the withering away of high-quality public provision of mental health services (where indeed they exist), and a threat to publicly funded training. Psychotherapy may survive either as a luxury good - or as merely merely a 'luxury good', a form of cultivation of the self, and as a treatment for mental illness for those families who can afford it. Or, as a response to severe need which is available without charge only from the most morally or politically committed voluntary agencies, or from certain surviving bastions of universalism in the state sector. 
It is clear that a significant sphere of small -scale 'artisanal' production of goods and services survives and even flourishes in the modern mass production/mass consumption economy. There is a segment of the middle class which is rich in what Bourdieu called 'cultural capital' (the outcomes of education and life-style choice) but has modest economic means, perhaps through opt-outs from conventional careerpaths, or through employment in lowly paid work. There is a significant but subordinate economic sector which provides for this 'sub-culture', through such agencies as farmers' markets, local art galleries, bakeries, bookshops, restaurants and the like. There are links between this economic sector and the visitor and tourist economies, since many who cannot afford or choose not to leave mainstream ways of making a living, enjoy experiencing something more 'characterful' in their leisure time. One can envisage the occupations of counselling and psychotherapy seeking refuge among this non-materialist segment of the middle class.

The development of capitalism brought the development of individualism, and idea that social well-being came from the individuals' pursuit of their own self-interest, in what RH Tawney (1920) called 'the Acquisitive Society'. But also what various writers have called 'individualisation' (Bauman 1992, Beck, 1992, Beck and BeckGernsheim 2002, Giddens 1991) the idea of a fuller cultivation of individual differences and powers of agency. In the nineteenth century there flourished both cultures of harsh instrumental individualism, and conceptions of expressive and ethical self-fulfilment, often formulated in terms highly critical of industrialism and the values of the market. The cultural liberation movements of the 1960 s were a reassertion of this latter current of feeliing, even though it soon became reabsorbed into the dominant cultures of consumption. These expressive currents have not been entirely suppressed, and people continue to seek therapies which offer possibilities of self-understanding and growth. It is hard, even according to the norms of the market to wholly discount the preferences that users of services, including mental health services, express when they are asked about what kind of therapy they prefer. However, patient choices and the prescribed evidence-based offer do not always coincide. 
My own view is that the outcome of these struggles to rationalise and marketise provision of mental health services is by no means a foregone conclusion. It must be remembered in any case that the purpose of mental health services is to lessen the sufferings of patients, not to enhance the quality of life of its providers, even though it is also the case that psychotherapy can be among the most fulfilling and satisfying of occupations.

Furthermore, not all forms of measurement, rationalisation, audit, and demands for 'evidence of effectiveness' are to be deplored or conceived to be destructive of value. Most of us are pleased, I imagine, that the system of air travel is subject to the most meticulous regulation, both of its machines and of its workforce. It seems almost a miracle to me that aeroplanes can cross the world in their millions, with such astonishlingly good records of safety. Similarly, anyone who has owned motor cars over a period of 50 years will probably have noticed the vast increase in reliability and efficiency that has taken place over that time, as a result of the scientific design of the systems of production and maintenance. When my wife recently had an operation to replace one of her hips, I was impressed by the degree to which this had become in recent years a routine medical procedure carrying little risk, and a high probability of success, even though what I think must be termed a human error led to her being allowed to fall to the ground and dislocate the new hip on the day after her operation, requiring another operation on the following day.

Of course, the question is how relevant are such procedures and ways of thinking to the provision of mental health treatment and care? Is it reasonable to say that they are not relevant, since individual psychotherapists already know all there is to know about mental suffering and its alleviation? It is on thing to know that some of the measures now being imposed on providers display a complete misunderstanding of their work, and another to say that all such_measures are wrongheaded and inappropriate. An example of a now-widely used measure of the first kind is the requirement that patients be asked to assess their satisfaction with psychotherapy at the end of every clinical session, a rule that misunderstands the entire theory and practice of dynamic psychotherapies, according to which patients may have to experience and tolerate some increased mental pain in order to gain some greater 
understanding of themselves. But the idea that one should know with reasonable certainty whether a method of treatment works or not, for defined categories of disorder, seems to me not absurd or destructive at all.

A large randomised controlled trial of three treatments for severe adolescent depression is currently in progress in three areas in England. There are over 500 patients, assigned to a year's treatment by CBT, once-weekly psychoanalytic child psychotherapy, or routine clinical care, with numerous measures (including post treatment follow-ups) of their outcomes. The child psychotherapists who have been responsible for the design of their part of the clinical input are satisfied that this corresponds well to the clinical practice they would normally follow, with some specific revisions, of which the most important are the initial randomisation to three kinds of treatment (patients do not choose which treatment they get) and the fact that the fixed term of the treatment was made explicit to patients and therapists from the outset.

We do not yet know the outcome of this trial. However one conclusion that has already been drawn from clinical experience of delivering it (and from a previous study Trowell (2012), is that not only may a fixed term of once-weekly treatment for a year not be harmful, compared with treatments without a predefined ending, but that it may even be beneficial especially to adolescent patients.It seems likely that training in time-limited therapy will now be added to the training requirements of the child psychotherapy profession. Should this trial prove successful in terms of treatment outcomes, it seems likely that NICE will take a much more favourable view than hiitherto of the value of psychoanalytic treatment at least for severe depressive illness.

From my long observation of and close acquaintance with child psychotherapy and some of its applications, I have never had any doubt of the remarkable improvements it often brings to the health and well-being of children and families.I have always thought that the problem that it does not work (surely one of the hidden fears of those most suspicious of measurement is that this is what will be found out), but rather that there had never been either the human or material resources 
availlable to investigate whether it does or not. It believe it is possible to respond to the current demands to provide evidence that psychotherapy can do a great deal of good in such a way as to strengthen the standing of and the resources available for this knd of provision.

However, in the end the future of psychotherapy and counselling and psychotherapy in this society will not depend only on the psychotherapy professions, and what they do in the face of threats to their existence. What is at risk under neoliberalism is surivial of the idea that society should support the self-development and selfunderstanding of all its citizens, as an aspect of a modern kind of democratic citizenship. It is the fate of this idea that will be crucial, and one hopes that psychotherapists and counsellors will be as active in society as other citizens to ensure that this larger battle is not lost.

\section{References}

Baumann, Z. (1992) Intimations of Postmodernity. London: Routledge.

Beck, U. (1992) Risk Society. London: Sage.

Beck, U.and Beck-Gernsheim, E. (2002) Individualization. London: Sage.

Danto, E.A. (2005) Freud's Free Clinics: Psychoanalysis and Social Justice. New York: Columbia University Press.

Foucault, (M.) The History of Sexuality, Volume I: An Introduction (New York: Vintage.

Foucault. M. (2006) Madness and Civilisation. New York: Vintage.

Giddens, A. (1991) Modernity and Self-Identity. Cambridge: Polity.

Marshall, T.H. (1950) 'Citizenship and Social Class', in Sociology at the Crossroads and other Essays (1963). London. Heinemann.

Porter, R. (2003) Madness: A Brief History. Oxford: Oxford University Press, Rustin, M.J. (1991) 'Psychoanalysis and Social Justice. In Free Associations (Pilot Issue) 1984, reprinted in The Good Society and the Inner World. London: Verso. Scull, A. (2005) The Most Solitary of Afflictions: Madness and Society in Britain, 1700-1900. Yale University Press.

Trowell, J. (Ed.). (2012). Childhood depression: A place for psychotherapy. London: 
Karnac. 